\title{
The effects of different doses of melatonin on lipid peroxidation in diet-induced hypercholesterolemic rats
}

\author{
Butun $\mathrm{I}^{1}$, Ekmekci $\mathrm{H}^{1}$, Ciftci $\mathrm{O}^{1}$, Sonmez $\mathrm{H}^{1}$, Caner $\mathrm{M}^{2}$, Altug $\mathrm{T}^{3}$, Kokoglu $\mathrm{E}^{1}$ \\ Department of Biochemistry, Istanbul University, Cerrahpasa Medical Faculty, Istanbul, Turkey. \\ hakekmekci@yahoo.com
}

\begin{abstract}
This study aims to see in an animal experiment how differently the low and high doses of melatonin affect the antioxidant status and peroxidation of lipids. Forty-two male Wistar-Albino rats weighing about 200 gr (180-220) aged 6-7 months were used. Of these rats, 12 were fed with normal rat chow for 12 weeks. The latter ones were divided into two groups, each containing 6 rats. Group 1 (control group) received daily intraperitoneal injections of $\mathrm{NaCl}(0.9 \%$; w/v). Group 2 was injected ethanol daily (4\%; v/v; i.p.) to see the effects of ethanol in which we dissolved melatonin. Thirty rats were fed with a diet enriched with cholesterol $(2 \% ; w / w)$, cholic acid $(0.5 \% ; \mathrm{w} / \mathrm{w})$ and propilthyouracil $(0.5 \% ; \mathrm{w} / \mathrm{w})$ for 12 weeks. These rats were divided into three groups each containing 10 rats. The low-dose group received melatonin $1 \mathrm{mg} / \mathrm{kg} / \mathrm{d}$; i.p. (group 3), the high-dose group received melatonin in a dose of $10 \mathrm{mg} / \mathrm{kg} / \mathrm{d}$; i.p. (group 4), and only the cholesterol group did not get any vehicle (group 5). Total cholesterol (TC), LDL cholesterol (LDL-C), total antioxidant capacity (TAC), oxidized LDL (oLDL) and TBARS lelvels were measured in all groups. The produced high-cholesterol diet increased LDL cholesterol. Melatonin decreased the extent of this plasma lipoprotein increase and also prevented the oxidation of it. This effect was clearer when the dose was higher. Antioxidant status seems to be also dose-dependent (Tab. 2, Ref. 33). Full Text in PDF www.elis.sk.

Key words: melatonin, oxidized LDL, lipid peroxidation, hypercholesterolemia, TBARS.
\end{abstract}

Coronary artery disease (CAD) is one of the leading causes of mortality and morbidity all over the world $(1,2)$. Traditional risk factors of CAD are age, sex, hypercholesterolemia, arterial hypertension, diabetes and smoking. One of the strongest risk factors is the high concentration of LDL-C (3). LDL particles are oxidized by free radicals in the intimal space of arteries. The oxidative modification of LDL increases its uptake by macrophages via scavenger receptors. This process ends with the formation of foam cells and atherosclerosis (4).

Melatonin secreted by the pineal gland is a powerful scavenger of free oxygen radicals, especially $\mathrm{OH}$ radicals and probably peroxyl radicals (5). There is also evidence that melatonin is also an indirect antioxidant as it promotes activities of a variety of antioxidative enzymes $(6,7-12)$. Exogenous melatonin has been shown to reduce the lipids. Plasma levels of LDL-C and TC were reduced by melatonin in hypercholesterolemic rats (13-16).

Oxidized low-density lipoprotein (oLDL) is an important factor in the initiation and progression of atherosclerosis (2). It leads the endothelial dysfunction and plaque destabilization through multiple mechanisms. LDL particles accumulate in the intimal space of arteries and are oxidized by free oxygen radicals. As

${ }^{1}$ Department of Biochemistry, Istanbul University, Cerrahpasa Medical Faculty, Istanbul, Turkey, ${ }^{2}$ Department of General Surgery, Istanbul University, Cerrahpasa Medical Faculty, Istanbul, Turkey, and ${ }^{3}$ Experimental Animal - Research and Breeding Laboratory, Istanbul University, Cerrahpasa Medical Faculty, Istanbul, Turkey

Address for correspondence: H. Ekmekci, Istanbul University, Cerrahpasa Medical Faculty, Department of Biochemistry, Fatih, Istanbul, Turkey. a result of lipid peroxidation, several non-radical products are formed, including malondialdehyde (MDA) and other reactive aldehydes. Melatonin, its precursors, as well as its breakdown products have been shown to prevent the oxidation of lipids (17) Because of all these hypolipidemic and antioxidative effects, this pineal indole has been used in many experimental studies as a vehicle in different ways and in different doses. It is suggested to be a physiological antioxidant by experimental data (12-16). In addition, a correlation between melatonin levels and blood antioxidant status has been suggested. Therefore, we aimed to add some new evidence about the latter by using melatonin in both low and high doses.

\section{Materials and methods}

\section{Design of the experiment}

Interventions concerning animals were performed according to the Guide for Care and Use of the Laboratory Animals. Forty-two male Wistar-Albino rats weighing about $200 \mathrm{~g}(180-220)$ aged 6-7 months were housed four or six per cage in a room maintained at $23-25{ }^{\circ} \mathrm{C}$ with 12 -hour light-dark cycles; the lights were off daily from 18:00 through to 06:00 for 12 weeks. Of the latter rats, 12 were fed with normal rat chow and divided into two groups of 6 rats each. Group 1 (control group) received daily intraperitoneal injections of $\mathrm{NaCl}(0.9 \%$; w/v). Group 2 was injected ethanol daily ( $4 \%$; v/v; i.p.) (group 2) to see the effects of ethanol in which we dissolved melatonin. Thirty rats were fed with a diet enriched with cholesterol $(2 \%$; w/w), cholic acid $(0.5 \%$; w/w) and propilthyo- 
Tab. 1. Results of serum oxidized LDL, total and LDL cholesterol, total antioxidant capacity and TBARS levels of the groups (mean \pm SD).

\begin{tabular}{lccccc}
\hline Variables & Group 1 $(\mathrm{n}=6)$ & Group 2 $(\mathrm{n}=6)$ & Group 3 $(\mathrm{n}=10)$ & Group 4 $(\mathrm{n}=10)$ & Group 5 $(\mathrm{n}=10)$ \\
\hline TC $(\mathrm{mg} / \mathrm{dL})$ & $62.63 \pm 13.83$ & $59.71 \pm 7.42$ & $168.31 \pm 26.6$ & $135.79 \pm 10.83$ & $201.8 \pm 24.43$ \\
LDL-C $(\mathrm{mg} / \mathrm{dL})$ & $15.71 \pm 12.54$ & $6.93 \pm 0.98$ & $108.89 \pm 24.12$ & $69.44 \pm 12.05$ & $121.61 \pm 24.97$ \\
TAC $(\mathrm{U} / \mathrm{L})$ & $252.16 \pm 11.37$ & $253.7 \pm 23.34$ & $346.2 \pm 33.45$ & $375.11 \pm 21.64$ & $231.7 \pm 29.88$ \\
oLDL $(\mathrm{U} / \mathrm{L})$ & $11.2 \pm 0.67$ & $17.68 \pm 2.33$ & $19.46 \pm 2.03$ & $16.61 \pm 3.3$ & $20.51 \pm 3.82$ \\
TBARS $(\mu \mathrm{mol} / \mathrm{mL})$ & $2.93 \pm 0.19$ & $4.53 \pm 0.17$ & $4.85 \pm 0.18$ & $3.69 \pm 0.27$ & $7.61 \pm 0.51$ \\
\hline
\end{tabular}

uracil $(0.5 \% ; \mathrm{w} / \mathrm{w})$. These rats were divided into three groups of 10 rats each. The low-dose group received melatonin in a dose of $1 \mathrm{mg} / \mathrm{kg} / \mathrm{d}$; i.p. (group 3), the high-dose group received melatonin in a dose of $10 \mathrm{mg} / \mathrm{kg} / \mathrm{d}$; i.p. (group 4), while only the cholesterol group did not get any vehicle (group 5). Melatonin, cholesterol and cholic acid were purchased from Sigma (St. Louis, MO, USA) and thiouracil from Dr. F. Frik. Melatonin was dissolved in absolute ethanol ( $4 \%$; $/ \mathrm{v}$ in $0.9 \% \mathrm{NaCl} \mathrm{w} / \mathrm{v})$, and this solution was prepared freshly three times a week. The animals were kept in wire-bottomed stainless steel cages and were given diet and water ad libitum. The experimental procedures used in this study met the guidelines of the Animal Care and Use Committee of the University of Istanbul.

\section{Biochemical analysis}

Twelve weeks from the start of experiment, the rats were fasted overnight and then anesthetized with sodium pentobarbital. The blood was collected in tubes by cardiac puncture. All serum samples were frozen at $-80{ }^{\circ} \mathrm{C}$ in aliquots until assayed.

\section{Measurement of lipid parameters}

Total cholesterol (TC) levels were indicated by enzymatic method (Diasis). LDL cholesterol was calculated by Friedewald Formula.

\section{Lipid peroxidation assay}

Serum oxidized LDL (oLDL) levels were measured with competitive ELISA method, which is based on monoclonal antibody mAb-4E6 by using kits from Mercodia. The degree of lipid peroxidation was estimated in terms of thiobarbituric acid-reactive substance (TBARS) value determined by malondyaldehide (MDA) formation. Briefly, one milliliter of acid solution containing $15 \%$ (w/v) trichloroaceticacid (TCA), $0.375 \%(\mathrm{w} / \mathrm{v})$ thiobarbituric acid (TBA) and $0.25 \mathrm{~N}$ hydrocloric acid $(\mathrm{HCl})$ was added to the samples and the tubes were closed with taps. After incubation at $95^{\circ} \mathrm{C}$ for 15 minutes, they were cooled. After centrifugation at 4,000 $\mathrm{G}$ for $5 \mathrm{~min}$, the absorbance of the supernatant was measured at $532 \mathrm{~nm}$.

\section{Assay of antioxidant capacity}

The determination of total antioxidative capacity is performed by the reaction of antioxidants in samples with a defined amount of exogenously provided hydrogen peroxide. After the elimination of a certain amount of the provided hydrogen peroxide, the residual hydrogen peroxide is determined colorimetrically by enzymatic reaction which involves the conversion of TMB into a colored product. After stopping the reaction, the samples were measured at $450 \mathrm{~nm}$ (ImmunDiagnostik).
Tab. 2. Correlations of serum oxidized LDL, total and LDL cholesterol, total antioxidant capacity and TBARS levels of the groups (mean \pm SD).

\begin{tabular}{|c|c|c|c|c|c|}
\hline & $\mathrm{TC}$ & LDL-C & TAC & oLDL & TBARS \\
\hline $\mathrm{TC}$ & & $\begin{array}{l}\mathrm{r}=0.977 \\
\mathrm{p}<0.001\end{array}$ & $\begin{array}{c}r=-0.100 \\
p>0.05\end{array}$ & $\begin{array}{c}\mathrm{r}=0.686 \\
\mathrm{p}<0.01\end{array}$ & $\begin{array}{l}\mathrm{r}=0.771 \\
\mathrm{p}<0.01\end{array}$ \\
\hline LDL-C & & & $\begin{array}{c}r=-0.080 \\
p>0.05\end{array}$ & $\begin{array}{l}\mathrm{r}=0.675 \\
\mathrm{p}<0.01\end{array}$ & $\begin{array}{l}\mathrm{r}=0.752 \\
\mathrm{p}<0.01\end{array}$ \\
\hline TAC & & & & $\begin{array}{c}\mathrm{R}=0.157 \\
\mathrm{p}>0.05\end{array}$ & $\begin{array}{c}\mathrm{r}=-0.424 \\
\mathrm{p}<0.01\end{array}$ \\
\hline oLDL & & & & & $\begin{array}{l}\mathrm{r}=0.821 \\
\mathrm{p}<0.01\end{array}$ \\
\hline
\end{tabular}

\section{Statistical analysis}

Conventional methods were used for calculating the means and standard deviation (SD). All results were expressed as mean \pm SD. Statistical analysis was performed using Kruskall-Wallis test to see if there is a significant difference between the groups. Then the groups were mutually compared with the Mann-Whitney U test. For correlation analysis, Spearman's correlations were used. Values of $\mathrm{p}$ equal to or less than 0.05 were considered significant.

\section{Results}

There was not any significant difference between the levels of serum TC, TAC of groups 1 and 2 but the LDL-C levels were significantly lower; TBARS and oLDL levels were significantly higher in group 2 when compared with those of group 1 .

In groups 3 and 4, total serum cholesterol, oxidized LDL, and TBARS levels were significantly lower; total antioxidant capacity levels were significantly higher than those in group 5. In group 4, serum TC, LDL-C, TBARS, and oLDL levels were significantly lower; TAC levels were significantly higher than those in group 3. Both of groups 3 and 4 had significantly higher TAC levels than groups 1 and 2 (Tab. 1).

According to Spearman's correlation test, there was a positive correlation between serum oLDL and LDL-C $(r=0.675 ; \mathrm{p}<$ $0.01)$, oLDL and TBARS $(\mathrm{r}=0.821 ; \mathrm{p}<0.01)$, as well as between LDL-C and TBARS $(r=0.752 ; \mathrm{p}<0.01)$ levels. A positive correlation was detected between serum TC and TBARS ( $\mathrm{r}=0.771$; $\mathrm{p}<0.01)$, as well as between TC and oLDL $(\mathrm{r}=0.686 ; \mathrm{p}<0.01)$ levels. Besides these, we found a negative correlation between serum TAC and TBARS levels $(r=-0.424 ; \mathrm{p}<0.01)$ (Tab. 2).

\section{Discussion}

Alongside high concentration of low-density lipoprotein (LDL), hypercholesterolemia has been implicated as a risk factor 
in the development of coronary artery disease (CAD). Since the oxidative modification of LDL leads to the whole process, there has been interest to investingate the relationship between oxidative stress and CAD. Melatonin is a highly potent endogenous radical scavenger protecting the biomolecules against oxidative modification (15). Melatonin administration has been shown to have no significant effect on plasma lipids and lipoproteins in rats on normal diet but diminishes the effects of high-cholesterol diet on lipid parameters $(14,17)$. The protective action of melatonin was manifested only following the induction of cholesterolemia in rats (16). Therefore, as the antioxidant system is a protector in situations like hypercholesterolemia, which can induce oxidative stress, melatonin seems to be an agent playing its metabolic role harder on the lipid side. Melatonin has been studied in different diseases in which the free radicals are suspicious to be triggering the pathogenesis. Especially the cardiovascular disease is one of the most studied fields about the melatonin's beneficial effects. Nevertheless, different doses have been used in different ways (20).

We used the clinically most relevant dietary model to monitor the lipid peroxidation induced by hypercholesterolemia and found that melatonin prevented peroxidation by its antioxidative properties. The purpose of this study was to investigate two different doses of melatonin. Şener et al. have found an intraperitoneal dose of $10 \mathrm{mg} / \mathrm{kg}$ of melatonin, to be protective against oxidative stress in a sepsis model (19). The same dose of melatonin was also used by Nam et al. in neuronal damage and found that melatonin depressed the lipid peroxidation nearly to the control levels (21). While these two studies were designed to be short term, Balkan et al were giving melatonin $(10 \mathrm{mg} / \mathrm{L}$ in drinking water) to rats for 4 months. They found that the melatonin treatment had an ameliorating effect on the disturbances in prooxidant-antioxidant balance in the liver of mice following cholesterol feeding (22). Administration of melatonin ( $10 \mathrm{mg} / \mathrm{kg} /$ day $)$ for 4 weeks in cadmium intoxicated rats diminished the levels of oxidative stress markers, lipid peroxidation, and protein carbonyls in brain while elevating the levels of nonenzymatic and enzymatic antioxidants (23). Considering the high dose of melatonin, these results were similar to ours. The present study demonstrates that high doses of melatonin lower the total and LDL cholesterol and oxidation parameters much more than low doses do. Besides this, the rats receiving a high dose have much more antioxidant capacity than those in the low-dose group. Group 2 received ethanol, and the results showed the well-known hypolipidemic effect of alcohol, especially on LDL-C. However, groups 3 and 4 received cholesterol-rich diet that enhanced the lipids as seen in group 5 . The ability of melatonin to lower LDL-C even in such a diet is inferred from our results. Lipid peroxidation is a basically degenerative reaction and its products such as TBARS are toxic to cells (24-26). As mentioned above, melatonin has been shown to be highly effective in protecting against oxidative damage caused by several factors such as aging, ischemia-reperfusion, toxins and hypercholesterolemia $(17,27-30)$. The present data also indicate the oxidant activity of ethanol on lipids. In the present investigation, in groups 3 and 4 , melatonin was found to reduce both the oxidized LDL and TBARS, which are the products of lipid oxidation caused by both hypercholesterolemia and ethanol.

\section{Conclusions}

As seen, many different studies use melatonin as an antioxidant agent, however in different doses. Its hypolipidemic and antioxidant effects are very clear and the results suggest the possibility that melatonin could be clinically applied. Our results also support the clinical use of melatonin to treat conditions in which lipid peroxidation is present. Since these findings may have clinical importance, additional studies in this field should be of high priority.

\section{References}

1. Gupta N, Gill K, Singh S. Paraoxonases: structure, gene polymorphism \& role in coronary artery disease. Indian J Med Res 2009; 130 (4): 361-368.

2. Rajasekaran A, Kalaivani M. Hypolipidemic and antioxidant activity of aqueous extract of Monascus purpureus fermented Indian rice in high cholesterol diet fed rats. Turk J Med Sci 2011; 41 (1): 25-32.

3. Hardoon SL, Whincup PH, Wannamethee SG, Lennon LT, Capewell S, Morris RW. Assessing the impact of medication use on trends in major coronary risk factors in older British men: a cohort study. Eur J Cardiovasc Prev Rehabil 2010; 17 (5): 502-508.

4. Wakatsuki A, Okatani Y, Ikenoue N, Kaneda C, Fukaya T. Effects of short-term melatonin administration on lipoprotein metabolism in normolipidemic postmenopausal women. Maturitas 2001; 38 (2): 171-177.

5. Korkmaz A, Reiter RJ, Topal T, Manchester LC, Oter S, Tan DX. Melatonin: an established antioxidant worthy of use in clinical trials. Mol Med 2009; 15 (1-2): 43-50.

6. Yaman H, Çayci T, Seyrek M, Akgul EO, Gulcan Kurt Y, Aydin I, Yaren H, Cakir E, Ozcan O, Cimen B, Turkozkan N, Erbil MK. Effects of vitamin A and $\mathrm{C}$ and melatonin on 3-nitrotyrosine formation in guinea pig heart under lipopolysaccharide-induced stress. Turk J Med Sci 2010; 40 (5): 715-721.

7. Tan DX, Chen LD, Poeggeler B, Manchester LC,Reiter RJ. Melatonin: a potent endogenous hydroxyl radical scavenger. Endocr. J 1993; 1: $56-60$.

8. Reiter RJ, Tan DX, Sainz RM, Mayo JC, Lopez-Burillo S. Melatonin: reducing the toxicity and increasing the efficacy of drugs. J Pharm Pharmacol 2002; 54 (10): 1299-1321.

9. Reiter RJ, Tan DX, Gitto E, Sainz RM, Mayo JC, Leon J, Manchester LC, Vijayalaxmi, Kilic E, Kilic U. Pharmacological utility of melatonin in reducing oxidative cellular and molecular damage. Pol J Pharmacol 2004; 56 (2): 159-170.

10. Reiter RJ, Tan DX, Maldonado MD. Melatonin as an antioxidant: physiology versus pharmacology. J Pineal Res 2005; 39 (2): 215-216.

11. Reiter RJ, Tan DX, Paredes SD, Fuentes-Broto L. Beneficial effects of melatonin in cardiovascular disease. Ann Med 2010; 6; 42 (4): 276-285.

12. Brzezinski A. Melatonin in humans. N Eng J Med 1997; 16; 336 (3): 186-195.

13. Damian E, Ianas O, Badescu I. Decrease in high-density lipoprotein cholesterol after administration of melatonin-free pineal extract in the rat. Endocrinologie. 1988; 26 (1): 17-20. 
$129-132$

14. Mori N, Aoyama H, Murase T, Mori W. Anti-hypercholesterolemic effect of melatonin in rats. Acta Pathol Jpn 1989; 39 (10): 613-618.

15. Kose K, Yazici C. The Effect of Levonorgestrel and Melatonin Treatments on Plasma Oxidant-Antioxidant System, and Lipid/Lipoprotein Levels in Female Rats. Turk J Med Sci 2000; 30; 523-528.

16. Chan TY, Tang PL. Effect of melatonin on the maintenance of cholesterol homeostasis in the rat. Endocr Res 1995; 21 (3): 681-696.

17. Hoyos M, Guerrero JM, Perez-Cano R, Olivan J, Fabiani F, Garcia-Perganeda A, Osuna C. Serum cholesterol and lipid peroxidation are decreased by melatonin in diet-induced hypercholesterolemic rats. J Pineal Res 2000; 28 (3): 150-155.

18. Kelly MR, Loo G. Melatonin inhibits oxidative modification of human low-density lipoprotein. J Pineal Res 1997; 22 (4): 203-209.

19. Sener G, Toklu H, Kapucu C, Ercan F, Erkanli G, Kacmaz A, Tilki M, Yegen BC. Melatonin Protects Against Oxidative Organ Injury in a Rat Model of Sepsis. Surg Today 2005; 35 (1): 52-59.

20. Erdemir F, Parlak BS, Ozyurt H, Boztepe O, Atis O, Sahin S. Antioxidant Effect of Melatonin in Systemic Circulation of Rats After Unilateral Testicular Torsion. Turk J Med Sci 2008; 38 (1): 1-6.

21. Nam E, Lee SM, Koh SE, Joo WS, Maeng S, Im HI, Kim YS. Melatonin protects against neuronal damage induced by 3-nitropropionic acid in rat striatum. Brain Res 2005; 7; 1046 (1-2): 90-96.

22. Balkan J, Sener G, Cevikbaş U, Keyer-Uysal M, Uysal M. Melatonin improved the disturbances in hepatic prooxidant and antioxidant balance and hepatotoxicity induced by a high cholesterol diet in C57BL/6J mice. Int J Vitam Nutr Res. 2004; 74 (5): 349-354.
23. Shagirtha K, Muthumani M, Prabu SM. Melatonin abrogates cadmium induced oxidative stress related neurotoxicity in rats. Eur Rev Med Pharmacol Sci 2011; 15 (9): 1039-1050.

24. Manda K, Ueno M, Anzai K. AFMK, a melatonin metabolite, attenuates X-ray-induced oxidative damage to DNA, proteins and lipids in mice. J Pineal Res 2007; 42 (4): 386-393.

25. Jialal I, Devaraj S. Low-density lipoprotein oxidation, antioxidants, and atherosclerosis:a clinical biochemistry perspective. Clin Chem 1996; 42 (4): 498-506.

26. Jialal I, Devaraj S. The role of oxidized low density lipoprotein in atherogenesis. J Nutr 1996; 126 (Suppl 4): 1053S-1057S.

27. Sener G, Balkan J, Cevikbaș U, Keyer-Uysal M, Uysal M. Melatonin reduces cholesterol accumulation and prooxidant state induced by high cholesterol diet in the plasma, the liver and probably in the aorta of C57BL/6J mice. J Pineal Res 2004; 36 (3): 212-216.

28. Sener A, Ozsavci D, Bingol-Ozakpinar O, Cevik O, YanikkayaDemirel G, Yardimci T. Oxidized-LDL and Fe3+/ascorbic acid-induced oxidative modifications and phosphatidylserine exposure in human platelets are reduced by melatonin. Folia Biol (Praha) 2009; 55 (2): 45-52.

29. Vijayasarathy K, Shanthi Naidu K, Sastry BK. Melatonin metabolite 6-Sulfatoxymelatonin, $\mathrm{Cu} / \mathrm{Zn}$ superoxide dismutase, oxidized LDL and malondialdehyde in unstable angina. Int J Cardiol 2010;144 (2): 315-317.

30. Zhu HQ, Cheng XW, Xiao LL, Jiang ZK, Zhou Q, Gui SY, Wei W, Wang Y. Melatonin prevents oxidized low-density lipoprotein-induced increase of myosin light chain kinase activation and expression in HUVEC through ERK/MAPK signal transduction. J Pineal Res 2008; 45 (3): 328-334.

Received April 3, 2012. Accepted December 17, 2012. 